\title{
PERPATAHAN FATIK MATERIAL ALUMINIUM 2024-T3 DENGAN PENGELASAN FSW
}

\author{
Pujono \\ Program Studi Teknik Mesin Politeknik Negeri Cilacap \\ djovent@yahoo.com
}

\begin{tabular}{|c|c|}
\hline & Abstrak \\
\hline $\begin{array}{l}\text { Kata Kunci: } \\
\text { Aluminium, FSW, Uji } \\
\text { Fatik, Uji Fractografi. }\end{array}$ & $\begin{array}{l}\text { Aluminium bersifat ulet, mudah dimesin dan dibentuk dengan kekuatan tarik untuk } \\
\text { aluminium murni sekitar } 4 \sim 5 \mathrm{kgffmm}^{2} \text {. Paduan aluminium seri } 2024-T 3 \text { merupakan } \\
\text { logam paduan yang memiliki weldability yang rendah sehingga sulit dilakukan proses } \\
\text { pengelasan karena kecenderungan mengalami retak panas (hot cracking) atau } \\
\text { keropos dan terjadi pengerasan endapan (precipitation hardening) saat pengelasan } \\
\text { akibat adanya segregasi unsur paduan tembaga (Cu). Salah satu metode pengelasan } \\
\text { untuk mendapatkan hasil pengelasan aluminium yang baik adalah dengan FSW } \\
\text { (friction stir welding). } \\
\text { Tujuan dari penelitian ini adalah untuk mengetahui bentuk dan jenis perpatahan pada } \\
\text { paduan aluminium dengan pengelasan FSW dengan perlakuan TTT. Perpatahan } \\
\text { dihasilkan dari uji fatik material. } \\
\text { Metode Penelitian dilakukan dengan pengelasan paduan aluminium plat 2024-T3 } \\
\text { menggunakan teknik FSW dengan perlakuan transient thermal tensioning (TTT). } \\
\text { Perlakukan panas (transient thermal) dilakukan dengan meletakkan pemanas sejajar } \\
\text { dengan tool/pin las. Kecepatan pengelasan FSW ditentukan adalah } 11 \text { mm / menit dan } \\
\text { 1200 rpm. Pengujian yang dilakukan yaitu uji fatik dan uji fractografi dengan SEM } \\
\text { Hasil penelitian menunjukkan jumlah siklus uji fatik adalah } 765.250 \text { siklus dengan } \\
\text { kurva berbentuk sigmoidal. Secara visual dan hasil uji fractografi dengan SEM } \\
\text { menunjukkan bahwa perpatahan yang terjadi adalah jenis patah getas. }\end{array}$ \\
\hline
\end{tabular}

Keywords:

Aluminium, FSW,

Fatigue test,

Fractography test

\begin{abstract}
Resilient, machine processed, shapped aluminium using pulling power for pure aluminium with 4-5kgf/ $\mathrm{mm}^{2}$. Aluminium fusion with series 2024-T3 is a metal fusion whose low weldability so it is very difficult to be conducted the welding process because it tends to occur hot cracking or being porous, and precipitation hardening when conducting welding process due to segregation of copper (Cu) fusion subtance. One of welding method to obtain the good aluminium welding result is by using FSW (friction stir welding).

The purpose of this research is to find out the shape and type of fracture on aluminium fusion with FSW welding by dealing TTT. The fracture is created from fatik substance test.

The reserach method was conducted by welding of plate aluminium fusion 2024-T3 using FSW technique by dealing transient thermal tensioning (TTT). Transient thermal was conducted by resigning heater line with weld tool/pin. The speed of determined FSW welding was $11 \mathrm{~mm} / \mathrm{minutes}$ and $1200 \mathrm{rpm}$. The conducted test was fatigue test and factografi test with SEM.

The result of the reserach shows that the number of fatik test cycle is 765.250 with sigmoidal curve visually. Then, the result of fractography using SEM shows that the occured fracture is brittle.
\end{abstract}

Alamatkorespondensi

E-mail: djovent@yahoo.com

ISSN : 2087-1627 


\section{PENDAHULUAN}

\subsection{Latar Belakang}

Aluminium adalah logam yang ringan dengan berat jenis 2.7 gram $/ \mathrm{cm}^{3}$ setelah Magnesium (1.7 gram $\left./ \mathrm{cm}^{3}\right)$ dan Berilium (1.85 gram $\left./ \mathrm{cm}^{3}\right)$ atau sekitar 1/3 dari berat jenis besi maupun tembaga. Konduktifitas listriknya $60 \%$ lebih dari tembaga sehingga juga digunakan untuk peralatan listrik. Aluminium merupakan logam yang reaktif sehingga mudah teroksidasi dengan oksigen membentuk lapisan aluminium oksida, alumina $\left(\mathrm{Al}_{2} \mathrm{O}_{3}\right)$ dan membuatnya tahan korosi yang baik. Namun bila kadar Fe, $\mathrm{Cu}$ dan Ni ditambahkan akan menurunkan sifat tahan korosi karena kadar aluminanya menurun. Penambahkan $\mathrm{Mg}$, Mn tidak mempengaruhi sifat tahan korosinya. Aluminium bersifat ulet, mudah dimesin dan dibentuk dengan kekuatan tarik untuk aluminium murni sekitar 4 5 $\mathrm{kgf} / \mathrm{mm}^{2}$

Paduan aluminium seri 2024-T3 merupakan logam paduan yang memiliki weldability yang rendah sehingga sulit dilakukan proses pengelasan karena kecenderungan mengalami retak panas (hot cracking) atau keropos dan terjadi pengerasan endapan (precipitation hardening) saat pengelasan akibat adanya segregasi unsur paduan tembaga $(\mathrm{Cu})$. Salah satu upaya untuk memperbaiki sifat sambungan las paduan alumninium adalah dengan menggunakan teknik las friction stir welding (FSW). FSW adalah sebuah metode pengelasan yang termasuk pengelasan gesek, yang pada prosesnya tidak memerlukan bahan penambah atau pengisi. Panas yang digunakan untuk menyatukan spesiman dihasilkan dari gesekan antara benda yang berputar ( $\mathrm{pin} /$ tool) dengan benda atau material yang dilas.

\subsection{Batasan Masalah}

Batasan masalah pada Penelitian ini yaitu : Pengelasan dengan metode friction stir welding (FSW) untuk material Aluminium 2024-T3. Rasio tegangan (R) yang digunakan untuk pengujian perambatan retak fatik adalah 0,1 . Pengujian Fractografi menggunakan metode SEM (scanning electron microscope).

\subsection{Tujuan Penelitian}

Penelitian ini bertujuan untuk mempelajari pengaruh parameter pada material terhadap perpatahan dari hasil uji fatik.

\section{LANDASAN TEORI}

\subsection{Proses Friction Stir Welding}

Pengelasan dengan metode friction stir welding (FSW) pada paduan aluminium telah digunakan dibeberapa industri untuk meningkatkan kualitas sambungan aluminium paduan (Deepa dan Sherif, 2007). Pengelasan friction stir welding
(FSW) merupakan teknik pengelasan yang dapat menyambung material dalam kondisi lumer (tidak mencapai titik cair). Prinsip dari proses FSW adalah material yang akan disambung dijepit cukup kuat supaya saat proses pengelasan tidak lepas/loncat. Sebuah pin dari baja dalam posisi berputar diarahkan pada lubang yang ada pada material dan bergerak maju pada garis las. Ketahanan fatik hasil las FSW lebih baik dibandingkan dengan las konvensional MIG atau TIG (Lomolino dkk, 2004), hal ini diperkuat oleh Ericson dkk, (2001), bahwa kekuatan fatik las FSW lebih tinggi dibandingkan dengan las TIG dan MIG. Area kritis dari umur fatik dapat ditentukan dengan menunjukkan peran dari mikrostruktur, kekerasan pada tahapan inisiasi retak (Ali dan Zaroog, 2008), hal ini diperkuat juga oleh Ali dkk (2008), yang dinyatakan pada penelitian selanjutnya.

\subsubsection{Mekanika Pengelasan FSW}

Konvensi dan terminologi las FSW dapat ditunjukkan pada Gambar 2.

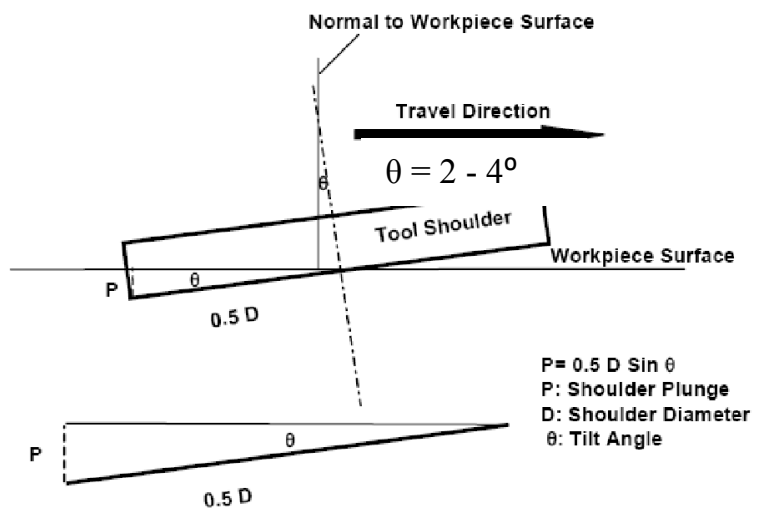

Gambar 2.1 Konvensi dan terminologi las FSW (Khaled, 2005)

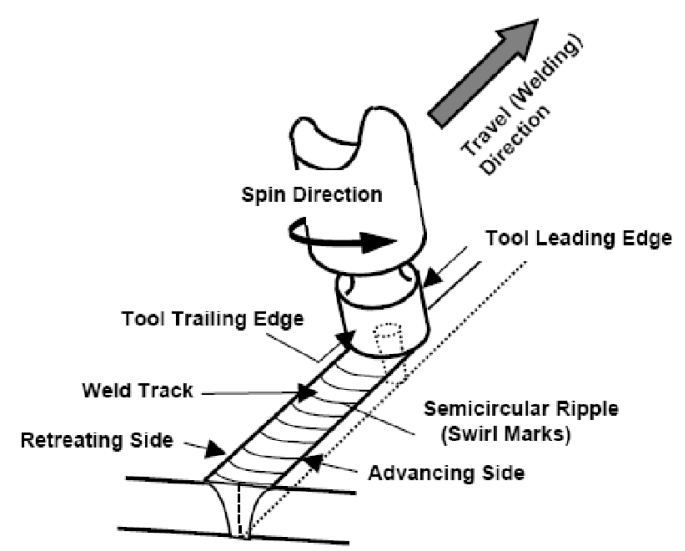

Gambar 2.2 Konvensi dan terminologi las FSW (Khaled, 2005)

Model kinematika las friction stir welding ditunjukkan pada Gambar 2.3 


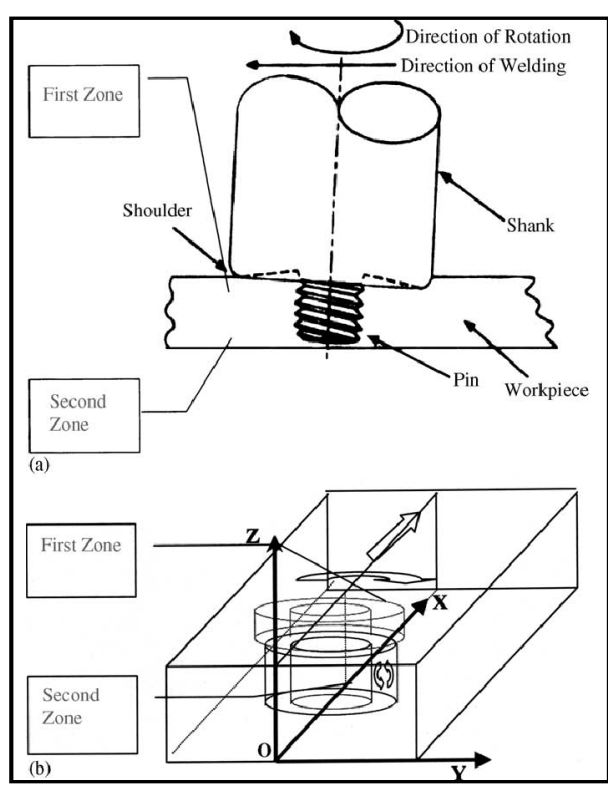

Gambar 2.3. Model kinematika las FSW (Heurtier dkk, 2005)

Pada pengelasan FSW, pin melakukan gerakan rotasi dan translasi, skema gerakan tersebut ditunjukkan pada Gambar 2.4.

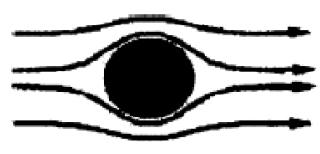

circumventing motion

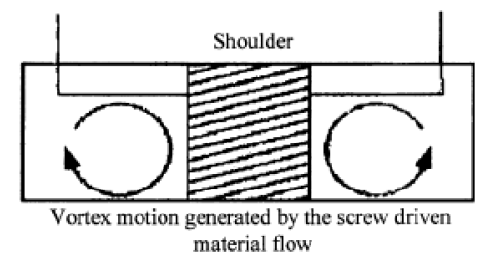

material flow

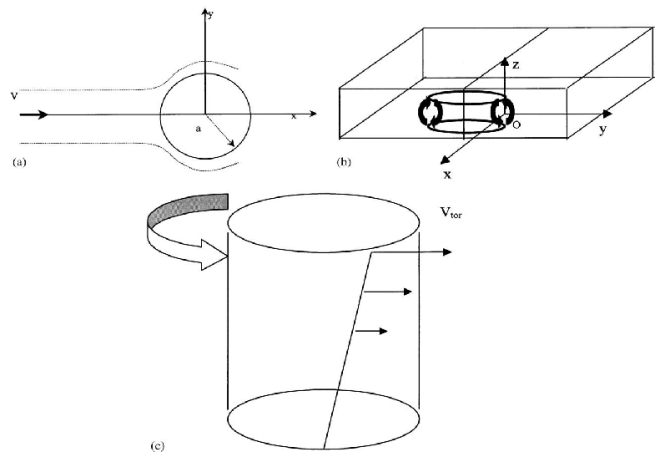

Gambar 2.4 Skema pergerakan pin,(a)

circumventing motion,(b) vortex motion (terjadi karena pin berupa screw),(c) torsional motion

(Heurtier dkk, 2005)

\subsection{Transient Thermal Tensioning (TTT)}

Proses TTT pada awalnya dilakukan untuk mengendalikan distorsi dengan menggunakan pemanasan untuk mengurangi besarnya tegangan sisa yang bisa menyebabkan tekukan (buckling). Proses TTT menggunakan prinsip penguatan tegangan termal, dan tidak memerlukan pendingian (quenching), dan dapat didesain secara mekanis untuk proses pengelasan. Proses transient thermal tensioning merupakan proses pemberian panas lokal pada daerah sekitar las dengan menggunakan sumber panas bergerak sehingga menghasilkan tegangan termal tarik saat pendinginan yang melawan tegangan sisa yang dihasilkan oleh proses pengelasanProses TTT telah dikembangkan di Edison Welding Institute (EWI) sejak pertengahan tahun 1990. Skema dari proses TTT ditunjukkan pada Gambar 2.5.

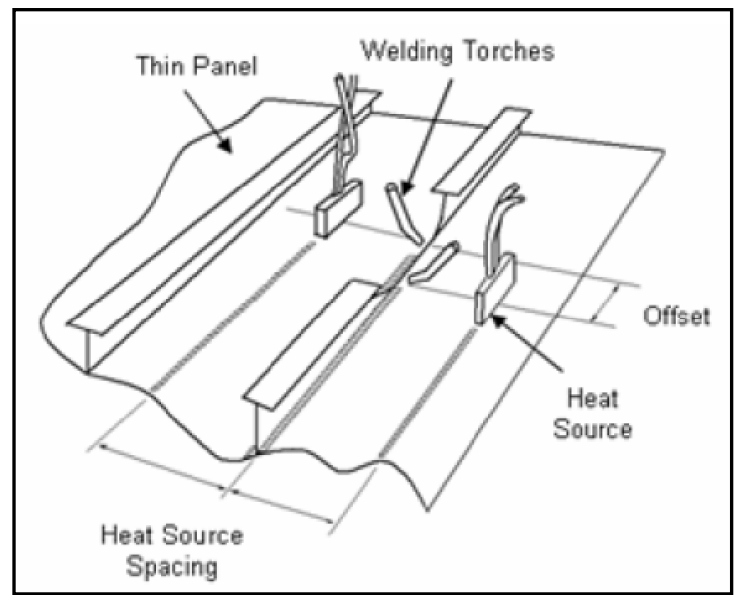

Gambar 2.5 Skema proses transient thermal tensioning (Huang dkk, 2006)

\section{METODE PENELITIAN}

\subsection{Material Penelitian}

Material yang digunakan pada penelitian adalah material aluminium paduan seri 2024-T3.

\subsection{Prosedur Pengelasan}

Proses pengelasan FSW yang dilakukan menggunakan mesin milling dengan perlakuan transient thermal dengan posisi penempatan heater di sejajar dengan alur las seperti pada Gambar 3.1 Dimensi ukuran probe/pin seperti Gambar 3.2 Kecepatan maju las $11 \mathrm{~mm} /$ menit dan putaran tool $1200 \mathrm{rpm}$. 


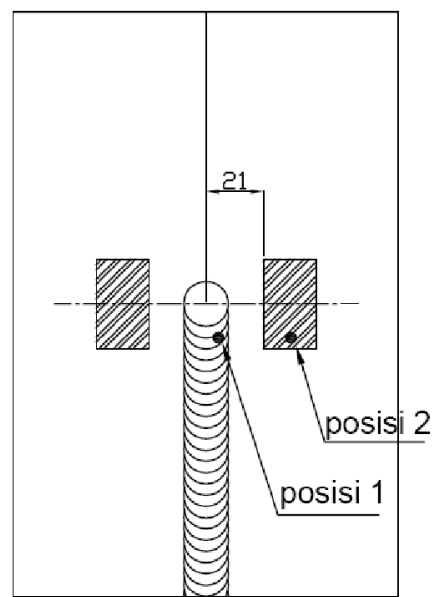

Gambar 3.1Posisi heaterdi sejajar dengan alur pengelasan FSW (satuan dalam mm)

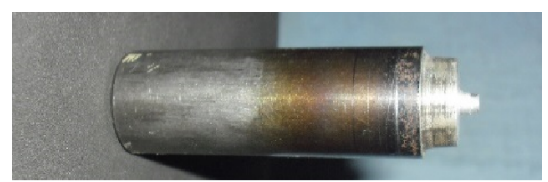

Gambar 3.2 Probe/Tool

Untuk pengelasan FSW dengan TT, digunakan rangkaian alat yang terdiri dari : mesin milling, panelbox heater, data loger box. Proses pengelasan FSW ditunjukkan pada Gambar 3.3.

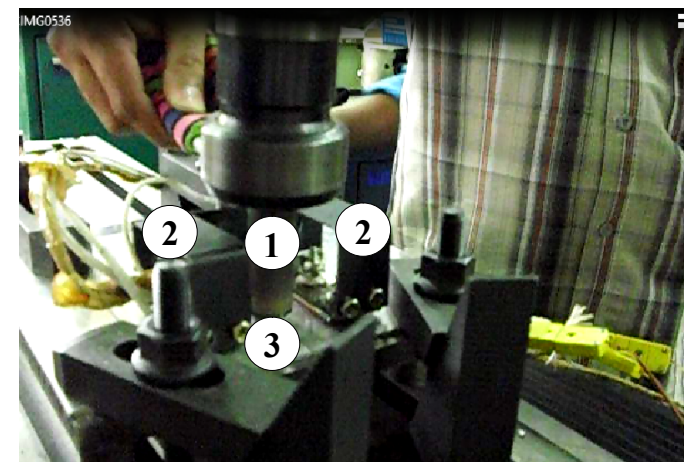

Gambar 3.3. Pengelasan FSW, (1) pin, (2) heater, (3) Al 2024-T3

\subsection{Uji Fractografi}

Uji Fractografi menggunakan SEM (Scanning Electron Microscope).

\subsection{Uji Fatik}

Pengujian Fatik dilakukan sesuai dengan standar ASTM E 647-00, beban yang digunakan sebesar 600kg, frekwensi $11 \mathrm{~Hz}$, Stress Ratio ( R ) 0,1 .

\section{HASIL DAN PEMBAHASAN \\ 4.1 Hasil Pengelasan FSW}

Hasil pengelasan FSW pada material aluminium seri 2024-T3 menunjukkan bahwa bentuk manik las secara visual terlihat rapi dan mampu menyatukan dua buah lembaran aluminium. Jarak rigi-rigi juga terlihat konstan. Hasil las FSW dapat dilihat pada gambar 4.1.

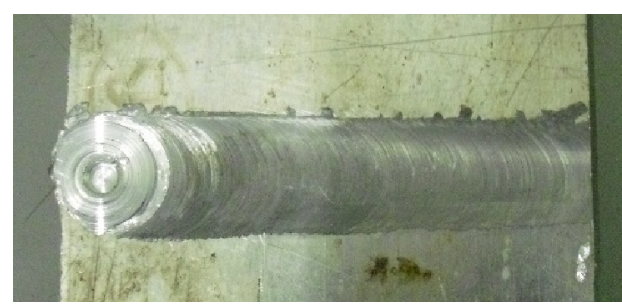

Gambar 4.1Hasil Las FSW

\subsection{Struktur Makro Las}

Pada foto struktur makrao terlihat daerah las atau bentuk kampuh yang cukup jelas. Hasil foto struktur makro pada las FSW pada material aluminium ditunjukkan pada Gambar 4.1. Friksi yang terjadi antara tool/pin dengan material aluminium menyebabkan panas sehingga aluminium mengalami pelunakan dan terjadi efek ekstrusi yaitu aliran logam plastis dari depan tool ke belakang tool sehingga pada sisi retreating terjadi deposit material, sedangkan pada bagian permukaan ditahan oleh tool. Pada foto struktur makro bisa ditunjukkan daerah weld/nugget, TMAZ dan HAZ.

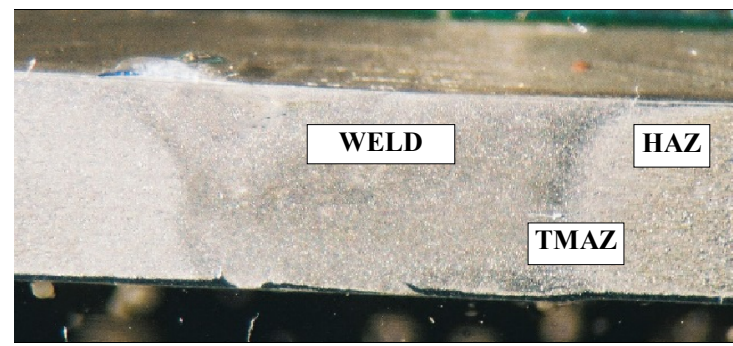

Gambar 4.2 Struktur Makro Las FSW

\subsection{Uji Fatik (kelelahan)}

Uji fatik yang dilakukan dengan standar ASTM E 647-00, beban yang digunakan sebesar $600 \mathrm{~kg}$, frekwensi $11 \mathrm{~Hz}$, Stress Ratio ( R ) 0,1 pada material dengan perlakuan las FSW dan pemanasan dengan heater posisi sejajar dengan alur las menghasilkan uji fatik berupa jumlah siklus yang ditunjukkan pada Tabel 2.

Tabel 2. HasilUjiFatik

\begin{tabular}{|c|c|c|}
\hline No. & Spesimen & Jumlah siklus \\
\hline 1. & Al 2024-T3 & 765.250 \\
\hline
\end{tabular}


Laju perambatan retak fatik mempunyai kurva dengan bentuk sigmoidal. Bentuk kurva sigmoidal dapat ditunjukkan pada Gambar 4.11

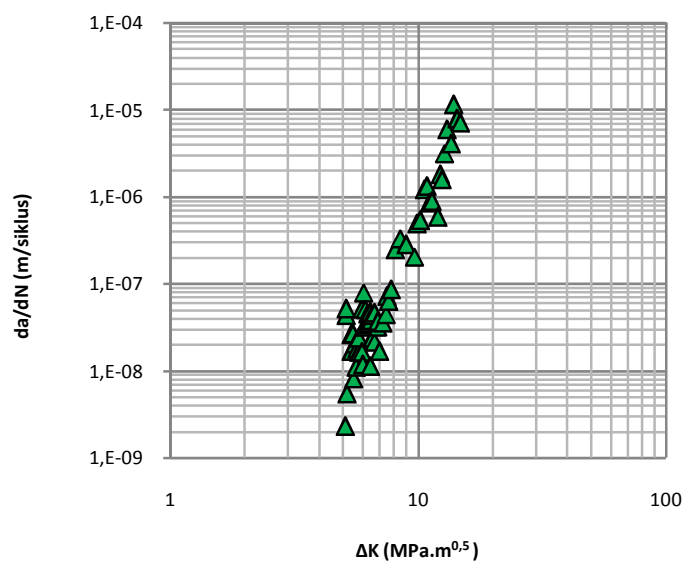

Gambar 4.3Hubungan antara da/dN dan $\Delta \mathrm{K}$ dalam skala $\log$.

\subsection{Uji Fractografi dengan SEM}

Uji fraktografi (SEM) dilakukan pada daerah patah fatik dengan mengambil titik pada daerah crack propagation, seperti ditunjukkan pada Gambar 4.4 dan Gambar 4.5, sedangkan hasil foto SEM pada daerah patah fatik di tunjukkan pada Gambar 4.6 Gambar 4.9

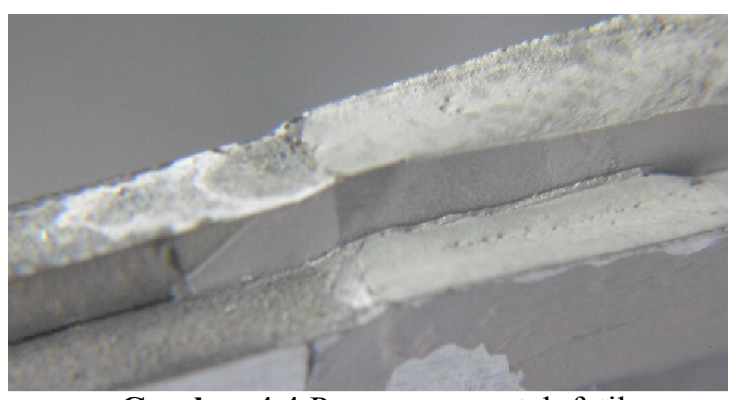

Gambar 4.4 Penampang patah fatik
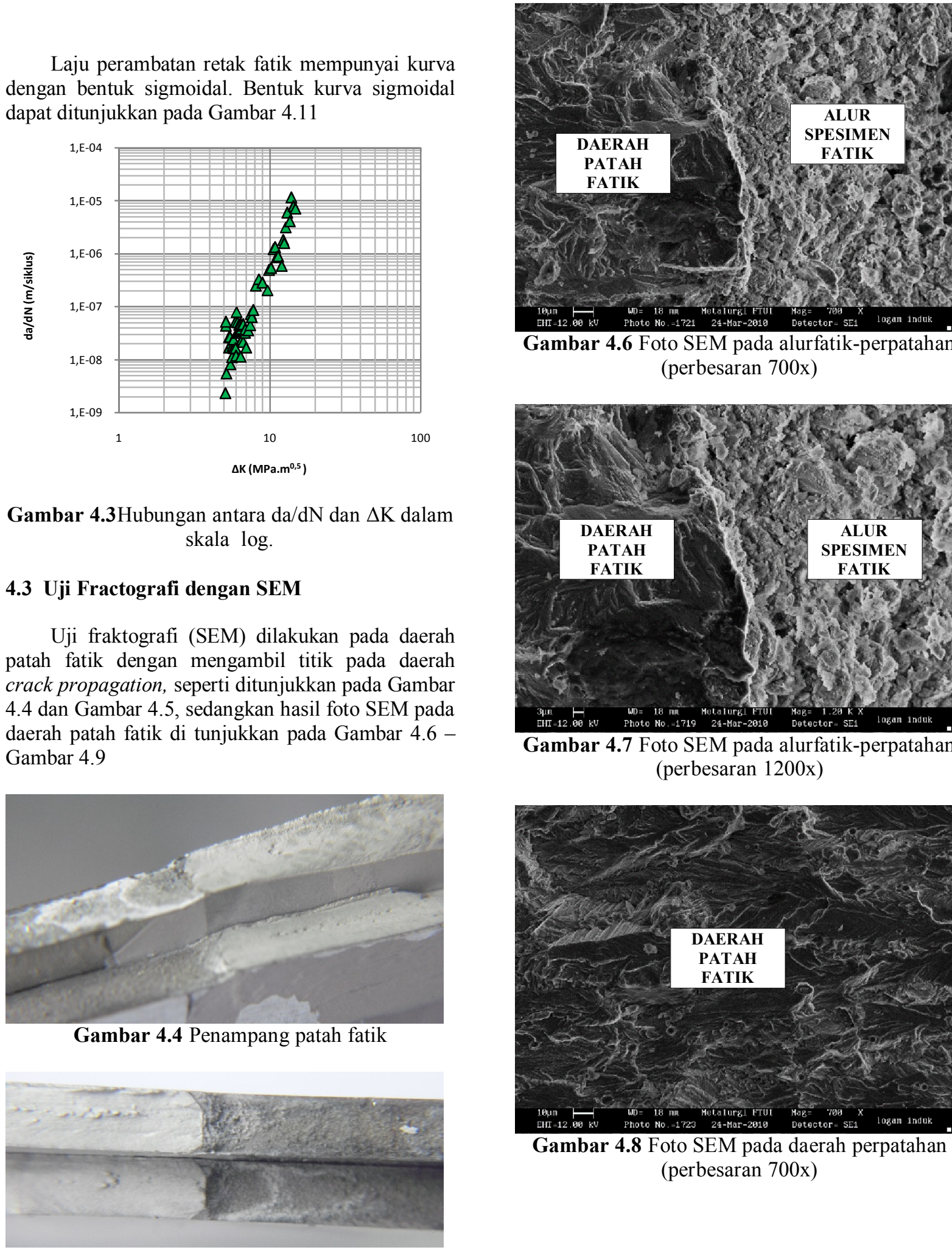

Gambar 4.6 Foto SEM pada alurfatik-perpatahan (perbesaran 700x)

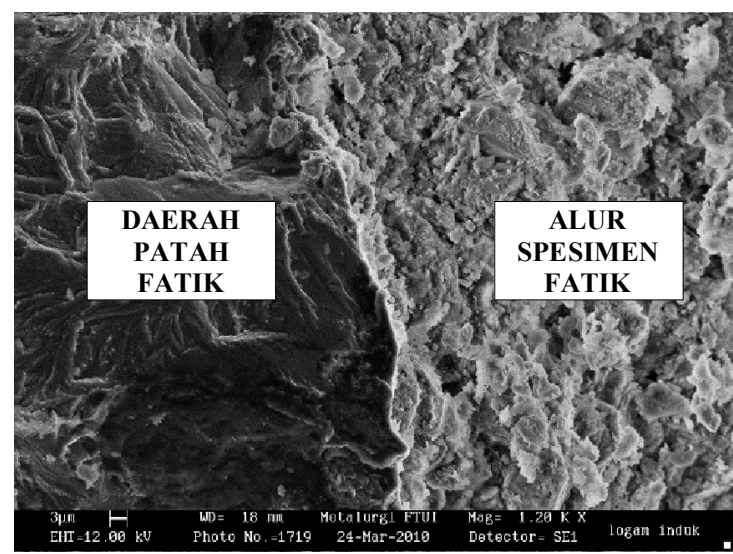

Gambar 4.7 Foto SEM pada alurfatik-perpatahan (perbesaran 1200x)

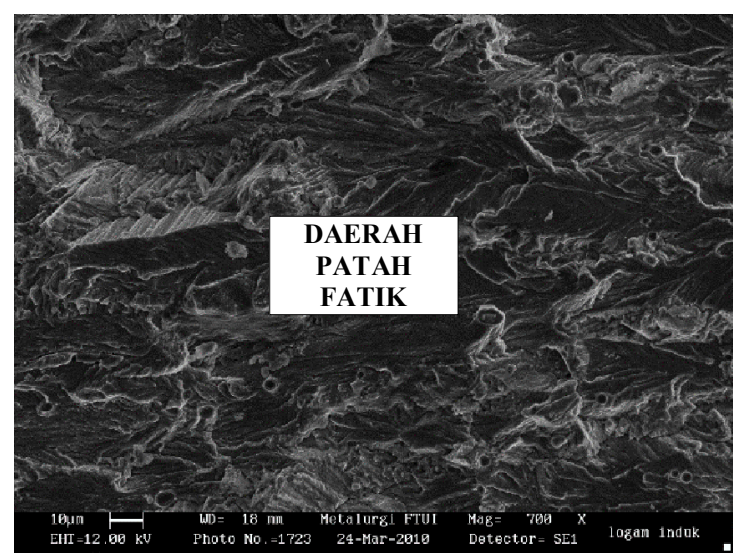

Gambar 4.8 Foto SEM pada daerah perpatahan (perbesaran 700x)

Gambar 4.5 Penampang patah fatik. 


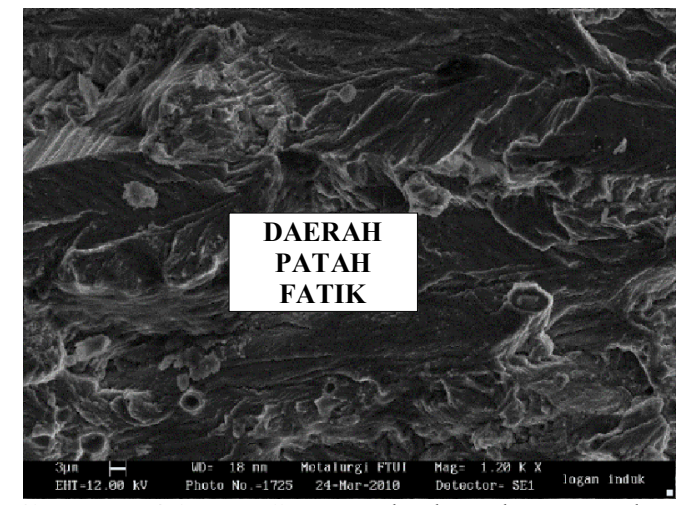

Gambar 4.9Foto SEM pada daerah perpatahan (perbesaran 1200x)

Gambar 4.6 - Gambar 4.9 memperlihatkan bahwa spesimen material AL 2024-T3 mengalami cleavage fracture atau patah getas. Fraktografi atau foto SEM memperlihatkan bahwa pada bidang patah nampak sebagai irregularitas-irregularitas kecil. Patah getas yang terjadi adalah transgranular fracture yaitu perpatahan yang memotong butirnya, karena bagian butir ini merupakan daerah yang paling lemah. Mekanisme perpatahan transgranular fracture ditunjukkan pada Gambar 4.22.

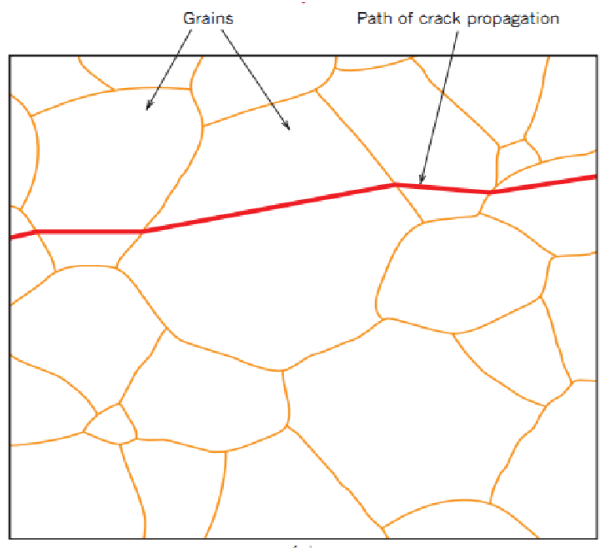

Gambar 4.10 Mekanisme perpatahan transgranular fracture

Pada transgranular fracture permukaan patahan mempunyai tekstur yang kasar atau bersegi banyak, hal ini disebabkan perbedaan orientasi dari satu butir ke butir yang lainnya.

\section{PENUTUP}

\subsection{Kesimpulan}

1. Hasil perpatahan pada spesimen las FSW dengan perlakuan TTT menunjukkan patah getas (cleavage fracture).

2. Patah getas yang terjadi menunjukkan jenis transgranular fracture.

\subsection{Saran}

Untuk penelitian selanjutnya perludilakukan pengujian tegangan sisa dan uji struktur mikro agar dapat diketahui dampak dari perlakuan TTT.

\section{DAFTAR PUSTAKA}

[1] Ali, A., Brown, M.W., Zaroog, O.S.,2008, Fatigue Damage of 2024-T351 Aluminium Alloy Friction Stir Welding Joints.part 1:Characterisation, Fatigue and Fracture Research Group, Department of Mechanical and Manufacturing Engineering, University Putra Malaysia, 43400 Serdang, Selangor, Malaysia

[2] Ali, A., Zaroog, O.S.,2008, Characterisation and Fatigue of Friction Stir Welding, Department of Mechanical and Manufacturing Engineering, University Putra Malaysia, 43400 Serdang, Selangor, Malaysia

[3] Deepa,R.A.,SherifE.,[2007], Characterization of Mechanical Properties and Study of Microstructure of Friction Stir Welded Joints Fabricated From Similar and Dissimilar alloys of Aluminium, Thesis, University of Missouri Columbia.

[4] Ericsson, M.,Sanstrom, R.,2001,Influence of Welding Speed on The Fatigue of Friction Stir Welds, and Comparison with MIG and TIG, Royal Institute of Tehcnology, Sweden.

[5] Heurtier, P., Jones M.J., Desrayaud, C., Driver J.H., Montheilet F., Allehaux D., 2005, Mechanical and thermal modelling of Friction Stir Welding, EcoleNationaleSup'erieure des Mines de Saint Etienne, Centre S.M.S., Departement M.M.F., UMR CNRS 5146Laboratoire PECM 158,Cours Fauriel, 42100 St. Etienne, France

[6] Huang, T.D., Conrardy, C., Dong, P., Kvidahl, L., Decan, L., [2006], Distortion Mitigation Technique for Lightweight Ship Structure Fabrication, Northrop Grumman Ship Systems, Society of Naval Architects and Marine Engineers, US.

[7] Khaled, T., 2005, An Out sider looks at FSW, ANM- 11 2N-05-06, Federal Aviation Adminstration, 3960 Paramount Boulevard, Lakewood CA 90712

[8] Lomolino,S., Tovo,R., Santos, J.D., 2004, Fatigue Behaviour of Friction Stir Welded Butt Joint in A6056 Alloy for Airframe Application, GKSS Forschungszentrum, Geesthacht, Germany. 